\title{
Hot-Spot Detection System with Correction of Operating Point for PV Generation System
}

\author{
Kazutaka Itako, Naoaki Iiduka, Tsugutomo Kudoh and Keishin Koh \\ Electrical \& Electronics Engineering Department, Kanagawa Institute of Technology, 1030 Shimo-Ogino, Atsugi 243-0292, Japan
}

\begin{abstract}
Currently, the production and the number of installations of PV (photovoltaic) modules have been increasing rapidly because of a feed-in tariff in Japan. Accordingly, the number of failures has also increased. Many failures are a result of the Hot-Spot phenomenon in which defective cell becomes hot when shadow occurs on the cell. On the other hand, if shadow occurs on normal cell, there are cases that $\mathrm{P} \& \mathrm{O}$ method that is MPPT (maximum power point tracking) control method incorporated in conventional PV system cannot track maximum power point and generated power decreases. The correspondence is required rapidly if these trouble occur. However, conventional PV system monitors generated power, correspondence is impossible by monitoring generated power. Previously, the authors developed real time Hot-Spot detection system that incorporates into PCS (power conditioning system). Thus, the authors developed plug-in type Hot-Spot monitoring system that includes "PV peak shift method" and confirmed effectiveness of the system in this time. "PV peak shift method" loads "Scan method" that is MPPT control method and measures I-V (current-voltage) characteristic by changing voltage of module from open to short by "Scan method" on a regular basis. The developed Hot-Spot monitoring system uses slope of I-V characteristic of PV module. Inserting developed system into already installed PV system, Hot-Spot can be easily monitored in real time and PV system can be operated at maximum power point.
\end{abstract}

Key word: PV generation system, Hot-Spot phenomenon, correction of operating point, plug-in type.

\section{Introduction}

Currently, the number of productions and installations of PV (photovoltaic) modules has been increasing rapidly because of a feed-in tariff in Japan. Accordingly, the number of failures of PV modules has also increased. Many failures are a result of the Hot-Spot phenomenon [1]. This is a phenomenon in which defective cell becomes hot when shadow occurs on the cell. This phenomenon causes breaking of the cell and a fire. While there is a conventional method for measuring temperature, such as using an infrared camera, for the purpose of checking for a Hot-Spot, the method requires a lot of time and effort. Recently, various studies have been performed about Hot-Spot [2-4]. For example, there is a study about Hot-Spot detection method using AC parameter characterization of PV module [5]. However, occurring Hot-Spot

Corresponding author: Kazutaka Itako, Ph.D., professor, research fields: power electronics and renewable energy. cannot be monitored on these studies while PV system is operating. Previously, the authors developed Hot-Spot detection method to module before installation using projector [6, 7]. However, Hot-Spot always occurs because of various factors even if the module is normal at checking for a Hot-Spot. In 2017, a feed-in tariff had been revised in Japan, and periodic maintenance to module after installation has been required. Therefore, it is desirable that Hot-Spot can be monitored while PV system is operating. However conventional PV system monitors generated power, detection of Hot-Spot is impossible by monitoring generated power. Previously, the authors developed to solve the problem real time Hot-Spot detection system that incorporates into PCS (power conditioning system) [8].

On the other hand, if shadow occurs on normal cell, there are cases that $\mathrm{P} \& \mathrm{O}$ method that is MPPT (maximum power point tracking) control method incorporated in conventional PV system cannot track 
maximum power point and generated power decreases. Previously, the authors developed to solve this issue "PV peak shift method" that corrects operating point to maximum power, and the authors confirmed effectiveness of the "PV peak shift method".

Thus, the authors developed plug-in type Hot-Spot monitoring system that includes "PV peak shift method" in this time. Inserting developed system into already installed PV system, Hot-Spot can be monitored in real time and PV system can be operated at maximum power point. "PV peak shift method" loads "Scan method" that is MPPT control method and measures I-V (Current-Voltage) characteristic by changing voltage of module from open to short by "Scan method" on a regular basis. The developed Hot-Spot monitoring system uses to detect Hot-Spot slope of I-V characteristic of PV module. This paper shows effectiveness of the developed system.

\section{Principle of Hot-Spot Monitoring System}

\subsection{I-V Characteristics of PV Module}

Table 1 shows the specifications of the PV module used in this study. These are values in the condition that air mass is 1.5 , irradiance is $1,000 \mathrm{~W} / \mathrm{m}^{2}$ and cell temperature is $25^{\circ} \mathrm{C}$. This module is mono-crystal.

Fig. 1 shows internal wiring diagram of the module. The module consists of 34 cells divided into two clusters. Bypass diodes are connected with parallel to the two clusters respectively. $\mathrm{V}_{\mathrm{cl}}[\mathrm{V}]$ is voltage of cluster. There is a Hot-Spot cell in the module. We measured I-V characteristics of PV module when shadow is not applied and shadow applied on cell. The shadow is applied on any normal cell or Hot-Spot cell. The patterns of shadow are 1 cell shadow shown in Fig. 2 or small shadow. The small shadow is about 3/4 to the cell.

Fig. 2 shows the measurement result of the I-V characteristics of the PV module. The condition at experiment is that irradiance is $900 \sim 950 \mathrm{~W} / \mathrm{m}^{2}$. Fig. $2 \mathrm{a}$ is I-V characteristics in the case of normal module. If shadow is applied to normal cell, the current of PV module decreases in area about $10 \sim 20 \mathrm{~V}$ that is high voltage side. Hereby, generated power decreases. Fig. $2 \mathrm{~b}$ is I-V characteristics in the case of Hot-Spot module. From this figure, shadow is applied to Hot-Spot cell, current has a negative slope to the voltage in area about 10 20 V that is high voltage side. This is reason that current flows to defective part in the cell. Abnormal temperature by Hot-Spot phenomenon occurs because current flows to defective part in the cell [9].

The developed system reduces decreasing generated power because of shadow and monitors occurring Hot-Spot phenomenon by introducing this system into already installed PV system.

\subsection{Hot-Spot Monitoring Method}

The developed Hot-Spot monitoring system uses slope of I-V characteristic of PV module in area of high voltage side. We found that current has a negative slope to the voltage in area of high voltage side in the case of Hot-Spot module. Thus, as shown in Eq. (1), the value calculating the current difference between the two points $V_{1}$ and $V_{2}$ volts was shown in Fig. 3 divided by the short circuit current $\left(I_{0}\right)$ and defines as current change rate.

$$
\text { Current change rate }=\frac{I_{1}-I_{2}}{I_{0}}
$$

Table 1 The specification of the PV module.

\begin{tabular}{ll}
\hline Index & Value \\
\hline Maximum power & $50 \mathrm{~W}$ \\
Voltage at maximum power & $15.9 \mathrm{~V}$ \\
Current at maximum power & $3.15 \mathrm{~A}$ \\
Open circuit voltage & $19.8 \mathrm{~V}$ \\
Short circuit current & $3.45 \mathrm{~A}$
\end{tabular}

Fig. 1 Internal wiring diagram of the module. 


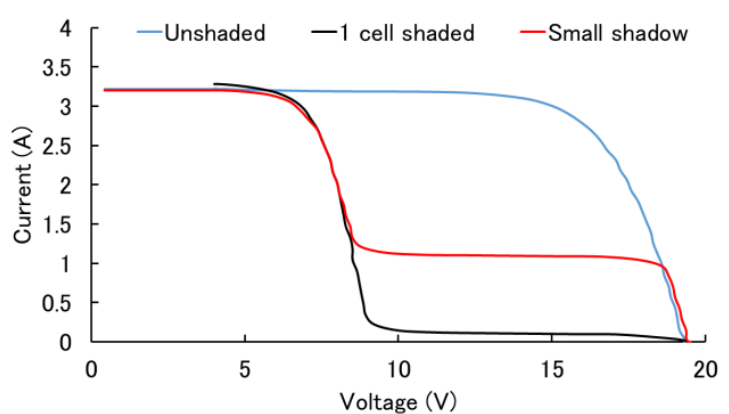

(a) Normal module

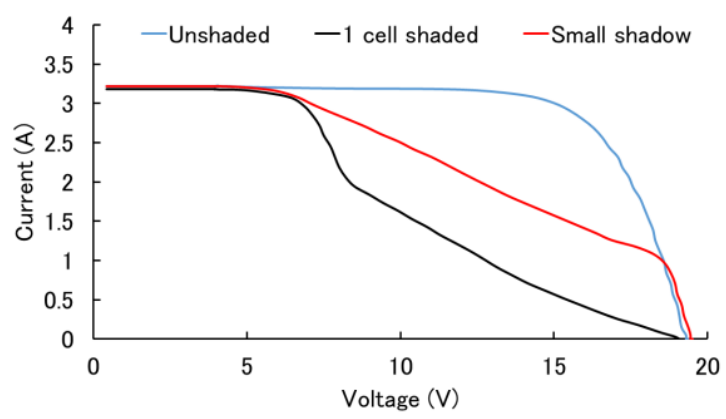

(b) Hot-Spot module

Fig. 2 I-V characteristics of the PV module.

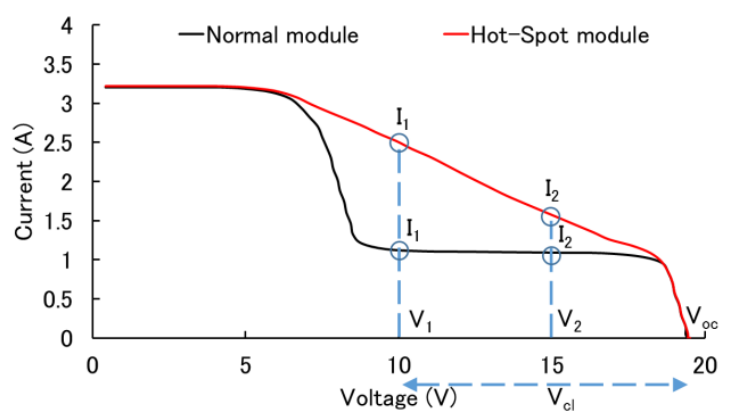

Fig. 3 I-V characteristics of the PV module at small shadow.

$V_{1}$ and $V_{2}$ are calculated by Eqs. (2) and (3). $V_{\mathrm{cl}}[\mathrm{V}]$ is voltage per the cluster, $V_{\mathrm{OC}}[\mathrm{V}]$ is open circuit voltage of module and $N$ is number of clusters.

$$
\begin{aligned}
& V_{1}=V_{O C}-V_{c l} \\
& V_{2}=V_{O C}-\frac{V_{c l}}{2}
\end{aligned}
$$

And, $V_{\mathrm{cl}}=V_{\mathrm{OC}} / N$.

Table 2 shows calculation results of current change rate of I-V characteristics shown in Fig. 2. The current change rate is more than 0.1 in the case of Hot-Spot module and less than 0.1 in the case of normal module. Moreover, we investigated relation of cells temperature to current change rate of other Hot-Spot module when shadow is applied to cells. Fig. 4 shows relation of cells temperature to current change rate when shadow is applied to cells. Optimal temperature of cell is $50 \pm 10^{\circ} \mathrm{C}$ when shadow is applied to cell (referring to JIS: Japanese Industrial Standard). A cell's temperature is more than $60{ }^{\circ} \mathrm{C}$ in the case that that current change rate is more than 0.1 shown in Fig. 4.

Thus, if current change rate of PV module is more than 0.1, the module can be judged as Hot-Spot module. The Hot-Spot monitoring system calculates current change rate, and detects Hot-Spot module.

\subsection{PV Peak Shift Method}

The developed Hot-Spot monitoring system includes "PV peak shift method". "PV peak shift method" corrects operating point to maximum power if shadow is applied to cell. With the $\mathrm{P} \& \mathrm{O}$ method that is the conventional MPPT algorithm in PCS of PV system, if partial shadow is applied to cell and multiple peaks are produced in the $\mathrm{P}-\mathrm{V}$ characteristics, there are cases that the PV system operates at a lower peak point. Thereby, the generated power decreases. Therefore, the authors developed "PV peak shift method" to overcome the issue. Fig. 5 shows conceptual diagram of "PV peak shift method". Multiple peaks $\left(\mathrm{P}_{1}\right.$ and $\left.\mathrm{P}_{2}\right)$ are produced in the $\mathrm{P}-\mathrm{V}$ characteristics. In this case, the $\mathrm{P} \& \mathrm{O}$ method operates

Table 2 Current change rate.

\begin{tabular}{lll}
\hline State of shadow & Normal module & Hot-Spot module \\
\hline Unshaded & 0.06 & 0.06 \\
1 cell shaded & 0.01 & 0.31 \\
Small shadow & 0.03 & 0.3 \\
\hline
\end{tabular}

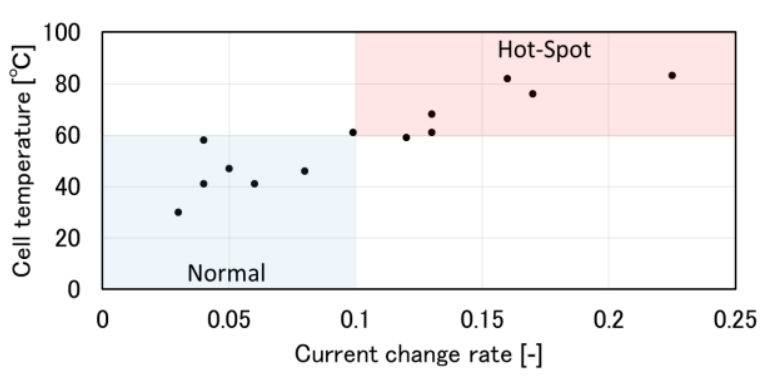

Fig. 4 Relation of cells temperature to current change rate. 
on the $\mathrm{P}_{2}$ which is lower peak. "PV peak shift method" outputs $\mathrm{P}-\mathrm{V}$ characteristics indicated by a broken line shown in Fig. 5 with PV peak shift operation. Herewith, the PV system operates in input possible voltage of the PCS and on $\mathrm{P}_{1}$ ' which is maximum power, shifting $\mathrm{P}_{1}$ to $\mathrm{P}_{1}$ '.

Using "PV peak shift method", the PV system can be operated at maximum power point even if shadow is applied on cell.

\subsection{Calculation of Current Change Rate by "Scan Method"}

When "PV peak shift method" operates at scan cycle $\left(T_{\mathrm{s}}\right), \mathrm{I}-\mathrm{V}$ characteristic is measured by changing voltage of module from open to short by using "Scan method" for detecting maximum power point. Fig. 6 shows Hot-Spot detection system which is buck-boost DC-DC converter that is principle diagram of Hot-Spot monitoring system. The $S_{1}$ and $S_{2}$ are turned off at scan cycle, PV module becomes open. Next, the $\mathrm{S}_{1}, \mathrm{~S}_{2}$ are turned on. Hereby, current $\left(I_{\mathrm{PV}}\right)$ of PV module is changed from 0 to short circuit current $\left(I_{\mathrm{SC}}\right)$. According to changing current, voltage $\left(V_{\mathrm{PV}}\right)$ of $\mathrm{PV}$ module is changed from open circuit voltage $\left(V_{\mathrm{OC}}\right)$ to 0 . As stated above, maximum power point is detected by changing $I_{\mathrm{PV}}$ and $V_{\mathrm{PV}}$.

"Scan method" measures I-V characteristics of PV module in order to detect maximum power point at scan cycle $\left(T_{\mathrm{s}}\right)$. Hot-Spot can be detected by calculating the current change rate by using "Scan method". The Hot-Spot monitoring system obtains $I_{\mathrm{SC}}$, $I_{1}$ which corresponds to $V_{1}$ and $I_{2}$ which corresponds

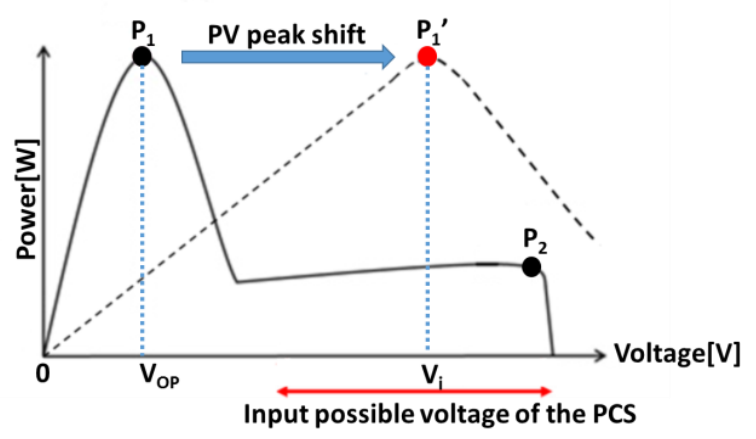

Fig. 5 Conceptual diagram of "PV peak shift method".

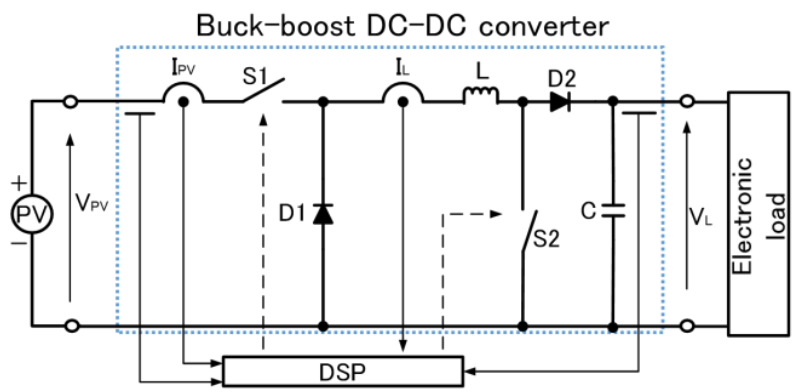

Fig. 6 Hot-Spot detection system.

to $V_{2}$ shown in Fig. 3 at scan cycle of "PV peak shift method", calculates the current change rate by Eq. (1), and detects the Hot-Spot in real time.

\section{Hot-Spot Monitoring System}

\subsection{Composition of the Hot-Spot Monitoring System}

Fig. 7 shows composition of the Hot-Spot Monitoring System at experiment. This system is structure that Hot-Spot detection system shown in Fig. 6 is inserted between PV module and electronic load. The output of PV module is sent to Hot-Spot detection system, and the system executes operation of "PV peak shift method" and Hot-Spot detection at scan cycle $\left(T_{\mathrm{s}}\right)$. Then, the system transmits output to PCS and monitor to confirm generation of Hot-Spot.

In this experiment, one module shown in Table 1 is used and PCS is emulated by operating P\&O method with DC-DC converter. The operating parameter of "PV peak shift method" is $V_{i}=22 \mathrm{~V}, T_{\mathrm{s}}=10 \mathrm{~s}\left(V_{i}\right.$ : the setting of input voltage of PCS [V], $T_{\mathrm{s}}$ : scan cycle [s]) and the operating of $\mathrm{P} \& \mathrm{O}$ method changes voltage of PV module by $1 \mathrm{~V}$ every $1 \mathrm{~s}$.

Fig. 8 shows flow of Hot-Spot detection system. The Hot-Spot Monitoring System is stand-by state (condition: PV module and PCS are direct coupling) at normal time, measures I-V characteristic of PV module at scan cycle $\left(T_{\mathrm{s}}\right)$. From the result of measuring, the system executes operation of "PV peak shift method". Thereafter, the system calculates current change rate. If the current change rate is more than 0.1 , module is judged as Hot-Spot module, and Hot-Spot flag is ON. On the other hand, the current 


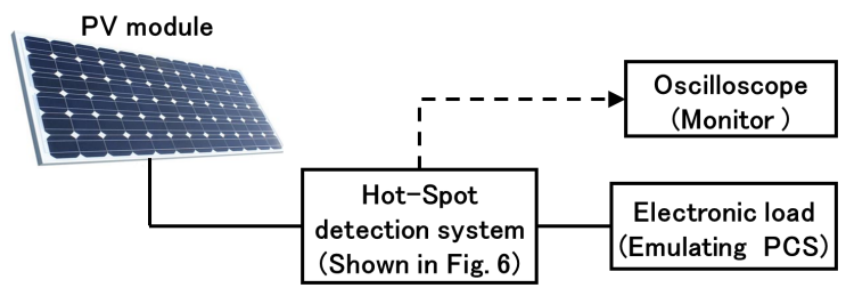

Fig. 7 Composition of the Hot-Spot monitoring system at experiment.

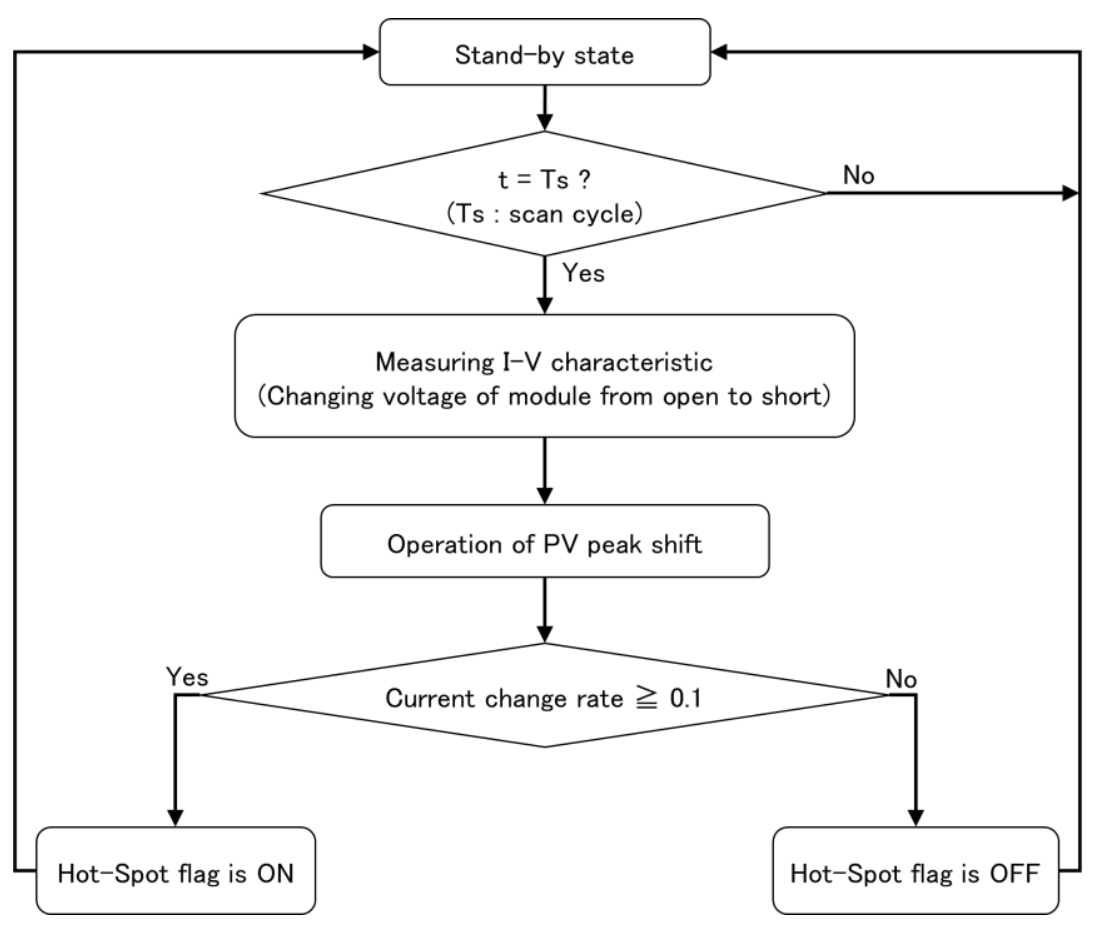

Fig. 8 Flow of Hot-Spot detection system.

change rate is less than 0.1 , module is judged as normal module, and Hot-Spot flag is OFF.

From the above flow, the developed Hot-Spot monitoring system operates.

\subsection{Experimental Result}

We experimented to confirm effectiveness of developed Hot-Spot monitoring system. The irradiance was $800 \sim 850 \mathrm{~W} / \mathrm{m}^{2}$ at experiment.

Fig. 9 shows the experimental results, Fig. 9a is in the case of normal module and Fig. $9 \mathrm{~b}$ is in the case of Hot-Spot module. Hot-Spot flag outputs $5 \mathrm{~V}$ when Hot-Spot occurs at $T_{\mathrm{s}}$. From Fig. 9a, the output power is decreased as a result of the shadowing normal cell at 3 seconds. In 10 seconds point, the scanning operation is performed and the output power is ensured to a certain level while the Hot-Spot flag remains 0 . In 32 seconds, the shadow is removed and the output power is increased while the flag also remains 0. From Fig. 9b, the output power is decreased as a result of the shadowing Hot-Spot cell at 3 seconds. In 10 seconds point, the scanning operation is performed, the output power is ensured to a certain level and the flag becomes $5 \mathrm{~V}$, so the Hot-Spot is detected. In 29 seconds, the shadow is removed and the output power is increased. In 30 seconds point, the scanning operation is performed, the flag becomes 0 .

Fig. 10 shows the module judged as Hot-Spot. From this figure, the cell temperature was more than $70{ }^{\circ} \mathrm{C}$. The cell temperature is abnormal.

Thus, it is proved that the developed Hot-Spot detection system can monitor Hot-Spot phenomenon. 


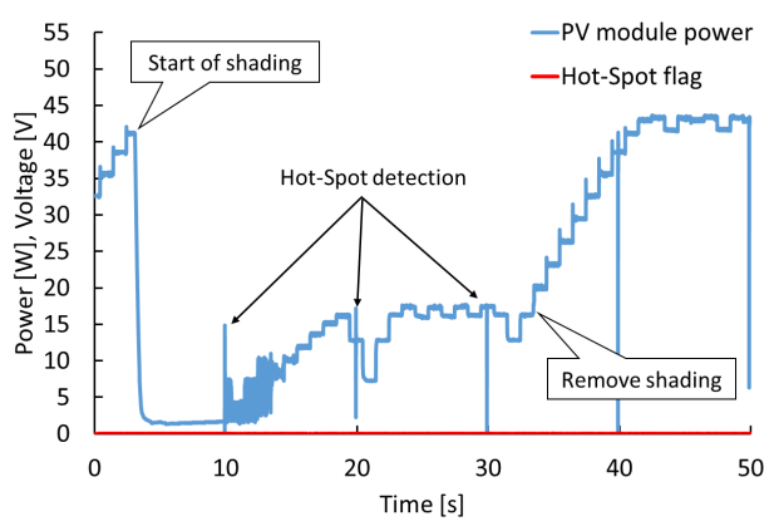

(a) Normal module

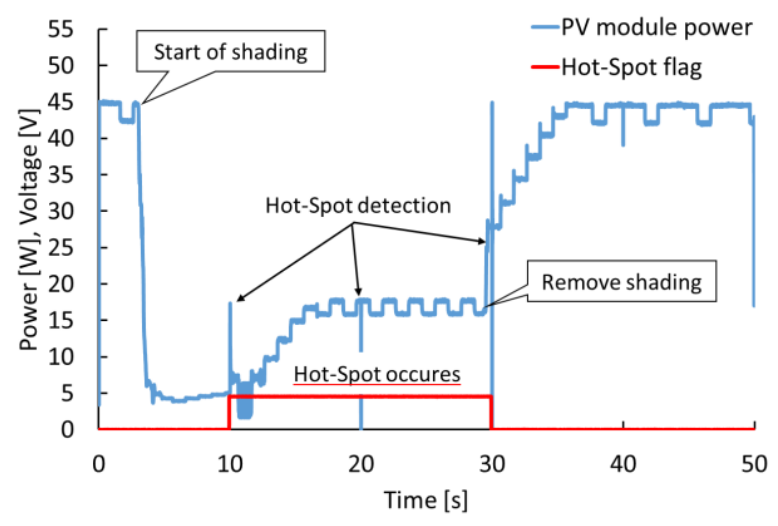

(b) Hot-Spot module

Fig. 9 The experimental results.

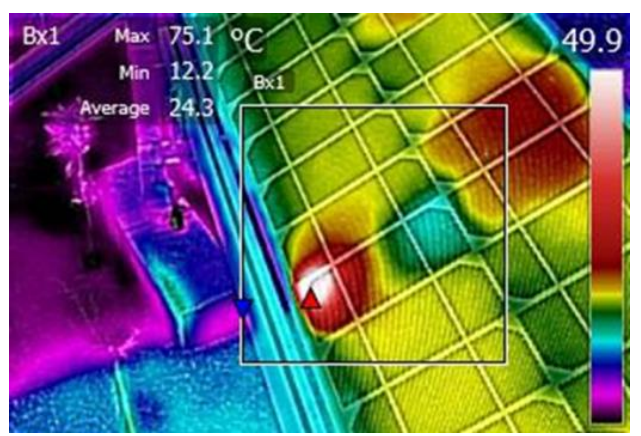

Fig. 10 Hot-Spot module.

\section{Conclusions}

We developed plug-in type Hot-Spot monitoring system that includes "PV peak shift method". From the experimental results, we confirmed that this system is able to distinguish between normal module and Hot-Spot module. Thus, validity of this system is verified. Inserting developed system into already installed PV system, Hot-Spot can be easily detected in real time and PV system can be operated at maximum power point if shadow is applied to a cell.

\section{References}

[1] Yasushi, O., Sanshiro, Y., and Daisuke, I. 2010. "An Investigation into Hot-Spot in PV Module." In Proceedings of JSES/JWEA Joint Conference.

[2] Moreton, R., Lorenzo, E., and Narvarte, L. 2014. "Dealing in Practice with Hot-Spots." In Proceedings of the 29th European Photovoltaic Solar Conference and Exhibition.

[3] Watanabe, S., Iijima, T., Ohya, H., Kudoh, T., and Itako, K. 2013. "Study on Temperature and Fundamental Characteristic of Hot-Spot of Single-Crystal Photovoltaic Cell by the Amount of Solar Radiation." In Proceedings of JSES/JWEA Joint Conference.

[4] Hoyer, U., Burkert, A., Auer, R., and Buerhop-Lutz, C. 2009. "Analysis of PV Modules by Electroluminescence and IR Thermography." In Proceedings of the 24th European Photovoltaic Solar Energy Conference and Exhibition-EUPVSEC.

[5] Kim, K. A., Seo, G. S., Cho, B. H., and Krein, P. T. 2015. "Photovoltaic Hot-Spot Detection for Solar Panel Substrings Using AC Parameter Characterization." IEEE Transactions on Power Electronics 31 (2): 1121-30.

[6] Wang, Y., Itako, K., Kudoh, T., Koh, K., and Ge, Q. 2016. "Voltage-Based Hot-Spot Detection Method for PV String Using Projector." In Proceedings of IEEE International Conference on Power and Renewable Energy, 570-4.

[7] Wang, Y., Itako, K., Kudoh, T., Koh, K., and Ge, Q. 2017. "Voltage-Based Hot-Spot Detection Method for PV String Using Projector." Energies 10 (2): 1-14.

[8] Itako, K., Hossam, B., Kudoh, T., and Koh, K. 2016. "Real Time Hotspot Detection System Using Scan-Method for PV Generation System." Journal of Energy and Power Engineering 10 (6): 378-83.

[9] Itako, K., and Kudoh, T. 2014. "Study on Hotspot of a Single-Crystal Photovoltaic Module." The Institute of Electrical Installation Engineers of Japan 34 (2): 140-6. 